\title{
Neonatal Screening for Metabolic and Endocrine Disorders
}

\author{
by Erik Harms and Bernhard Olgemöller
}

\section{SUMMARY}

Background: Neonatal screening for treatable endocrinopathies and inborn errors of metabolism is an important preventive measure. Advances in the diagnosis and treatment of these diseases have made it necessary to expand the screening program.

Methods: This article is based on a selective literature review and our clinical experience.

Results: In 2005, neonatal screening in Germany was expanded from 3 to 14 diseases, as mandated by the responsible governmental authority (the Gemeinsamer Bundesausschuss, i.e., Joint Federal Committee). From 2005 to 2008, screening revealed diseases requiring treatment in 1932 out of a total of 2758633 newborns (prevalence, 1 in 1428). The expansion of the screening program resulted in a $57 \%$ increase in the overall number of cases detected and a $92 \%$ increase for metabolic diseases alone.

Conclusion: The German neonatal screening program for treatable endocrinopathies and inborn errors of metabolism is a complex and integrated preventive measure that has become markedly more effective as a result of its expansion in 2005.

\section{- Cite this as:}

Harms E, Olgemöller B: Neonatal screening for metabolic and endocrine disorders. Dtsch Arztebl Int 2011; 108(1-2): 11-22. DOI: 10.3238/arztebl.2011.0011

Klinik für Kinder- und Jugendmedizin - Allgemeine Pädiatrie - der Westfälischen Wilhelms-Universität Münster, Prof. Dr. med. Harms

Labor Becker, Olgemöller \& Kollegen, München: Prof. Dr. med. Dr. rer. nat. Olgemöller

\begin{abstract}
creening for treatable congenital endocrinopathies - and metabolic disorders is an important preventive measure that is available for all neonates in Germany. Advances in the treatment of congenital metabolic defects have led to the expansion of the screening program to include a greater number of target diseases. The introduction of tandem mass spectrometry (TMS) has made it possible to broaden the spectrum of detectable congenital metabolic diseases. Since 2005, the statutory health insurance carriers in Germany have covered this type of expanded neonatal screening.
\end{abstract}

\section{The learning objectives for readers of this article are}

- to become aware of the importance of neonatal screening, the scope of the current screening program in Germany, and the diseases that are diagnosed by it;

- to be familiar with the procedure of neonatal screening and with the allocation of responsibilities for it, the potential sources of error, and the degree of urgency of any necessary intervention;

- to understand the special status of neonatal screening as a type of population-wide (predominantly) genetic testing.

This article is based on a selective literature review and on the authors' long experience as head of a screening laboratory and as President of the Committee on Screening of the German Society for Pediatrics and Adolescent Medicine (Deutsche Gesellschaft für Kinder- und Jugendmedizin, DGKJ).

\section{Case illustrations}

These two cases will serve to illustrate the necessity for the updating and expansion of the screening program, which took place in 2005 .

\section{Coverage}

$99.5 \%$ of all newborn babies in Germany undergo neonatal screening. 


\section{Case 1}

The parents, who are in good health and not related to each other, have three children who have been developing normally till now after unremarkable pregnancies and deliveries. Their youngest son became ill at the age of 23 months with gastroenteritis and vomiting. Although he lost less than $5 \%$ of body weight, his consciousness became progressively impaired, and he had epileptic seizures. On admission to the pediatric intensive care unit, he was comatose and laboratory testing revealed hypoglycemia, elevated transaminase levels, and hyperammonemia, but no ketosis. A diagnosis of Reye syndrome was made. Further testing revealed that the cause was medium-chain acyl CoA dehydrogenase (MCAD) deficiency, the most common defect of fatty acid beta-oxidation.

Comment: MCAD deficiency is inherited in an autosomal recessive pattern (frequency ca. $1: 10$ 000) and becomes clinically overt only when the individual is in a catabolic state, e.g., in the setting of fever, vomiting, or prolonged fasting. The situation of the patient described above is typical and can lead to death or permanent damage. If the metabolic defect is known in advance, the clinical manifestations of the disease can be prevented by suitable dietary management and/or intravenous infusion therapy (1).

\section{Case 2}

The parents are well, but consanguineous. Their first child was born at term after an uncomplicated pregnancy and delivery. A pediatrician examining the baby on the day of birth found nothing abnormal, and the mother and child were discharged from the hospital three days postnatally after an unremarkable preventive check-up ("U2"). From the $6^{\text {th }}$ day of life onward, the baby began to drink poorly and sleep excessively. Over the ensuing few days, signs of a rapidly progressive encephalopathy appeared, with alternating muscle tone (hypo-/hypertonia), dystonic arm extension, opisthotonus, hypothermia, epileptic seizures, apnea, and coma. The physicians who admitted the child to the intensive care unit noticed an unusual, sweet odor. Marked ketosis was found in the urine, giving rise to the suspicion of maple syrup urine disease, which was confirmed by amino acid analysis. Protein was removed from the child's diet, an anabolic state was restored through the administration of glucose, insulin, and potassium, and continuous venovenous hemofiltration was begun. Dietetic therapy was also initiated, with the aim of lowering the intake of branched-chain amino acids.

Comment: This is a typical case of neonatal maple syrup urine disease (MSUD). Because the child's metabolic defect was compensated for until birth by maternal metabolism acting via the umbilical cord, there was an asymptomatic interval from birth until the toxic metabolites had time to accumulate. If the disease is diagnosed by metabolic screening during this interval, decompensation of the type described above can be prevented. Once decompensation occurs, permanent damage to the central nervous system may ensue despite successful acute treatment (2).

\section{The development of neonatal screening}

The introduction of universal screening of all newborn babies for treatable congenital diseases was closely linked to the story of phenylketonuria, a disease for which Horst Bickel, in 1953, first described an efffective dietetic treatment (3). It was soon realized that the long-term success of this treatment essentially depends on its initiation before the onset of clinically overt disease. In the early 1960s, Robert Guthrie and Ada Susi developed a bacteriological test for phenylalanine that became known around the world as the Guthrie test (4). From about 1968 onward, all newborn babies in (West) Germany were tested in this way for an elevated serum concentration of phenylalanine. Galactosemia was the second congenital metabolic disease to be included in the screening program. The program underwent further major expansions to include thyrotropin screening for congenital hypothyroidism in the 1970s (5) and, in some of the German federal states, 17-OHprogesterone screening for adrenogenital syndrome in the 1990s (6).

As more and more cases of congenital metabolic defects came to be successfully treated, it was found that the established neonatal screening program did not cover the existing need. An ever-increasing number of diseases were understood to be treatable in principle if the treatment could be initiated in the presymptomatic stage, i.e., before the earliest overt manifestations of the disease, and this could only happen if there were a screening method for early detection. Yet these diseases were of highly varied types, and mostly rare as well; thus, with conventional diagnostic technology, many individual tests would have been required, and the case-finding cost

\section{Autosomal recessive MCAD deficiency}

If the metabolic defect is diagnosed before overt clinical manifestations develop, these can be prevented by a suitable diet and/or intravenous therapy.

\section{Maple syrup urine disease}

Maternal metabolism compensates for the child's metabolic defect until birth. After birth, there is an asymptomatic interval during which toxic metabolites accumulate that cannot be disposed of by the child's metabolism. 
(i.e., the total cost of all the tests required in the population to diagnose the disease in a single patient) would have been prohibitively high. The essential development that circumvented this problem was the introduction of tandem mass spectrometry (TMS) for neonatal screening in the 1990s (7). TMS made it possible to test for a large number of disorders of amino acid metabolism, organic acid metabolism, and fatty acid degradation simultaneously in a single procedure carried out on a single blood specimen.

In the period 1999-2001, a model trial was carried out in the German state of Bavaria, financed by the statutory health insurance carriers, in which the Guthrie test cards of more than 300000 neonates were studied by TMS in order to demonstrate the benefit of TMS for population-wide neonatal screening. Through the introduction of AGS (adrenogenital syndrome), biotinidase, and TMS screening, the model trial was able to identify considerably more neonates with congenital metabolic diseases and endocrinopathies than had previously been possible $(8,9)$. At the same time, the percentage of false positive findings was markedly reduced. In 2002, on the basis of these clearly favorable results, the Screening Committee of the German Society for Pediatrics and Adolescent Medicine (Deutsche Gesellschaft für Kinder- und Jugendmedizin, DGKJ) stipulated in its screening guidelines that TMS should be used instead of the Guthrie test and should be generally applied as the standard technique for metabolite screening (10).

\section{Goals of neonatal screening and requirements for neonatal screening programs}

Neonatal screening is a preventive medical measure. Its goals are the universal early diagnosis of treatable endocrine and metabolic diseases in neonates, followed by the timely initiation of effective treatment. The principles of population-wide screening for disease that were formulated by Wilson and Jungner in 1968 at the behest of the WHO remain valid today (11): Any disease for which screening is performed must be a serious condition whose etiology and pathogenesis are understood, which becomes clinically manifest only after a latent or early symptomatic stage, which can be treated successfully with the available medical and organizational resources, and for which suitable testing methods exist. In view of the recent technical developments that have enabled extensive predictive diagnostic testing for genetic disease, new proposals have been formulated for updated and more general requirements for screening programs (12). The selection of diseases for inclusion in a screening program is also based, in part, on economic considerations. Screening that leads to the early detection of phenylketonuria (PKU) and MCAD is not only beneficial to the patients whose conditions are diagnosed, but also highly beneficial in the economic sense $(13,14)$. It remains to be seen whether this is true for other, very rare diseases as well.

Although the criteria of Wilson and Jungner are still considered the gold standard for the establishment of screening programs, problems now arise in their strict implementation that were not foreseeable at first but that are nonetheless significant, especially with regard to the selection of target diseases for screening. All of the current target diseases for neonatal screening are of genetic origin, with the exception of congenital hypothyroidism (most cases of which are not genetic), yet the individual phenotype of a genetically determined disease can be highly variable. Thus, at the time that neonatal screening is performed, one cannot necessarily predict reliably whether a disease state, i.e., a phenotype that requires treatment, will ever develop. Variability of this kind complicates not just the determination whether treatment is needed, but also the judgment whether any treatment actually provided has been successful, for, in the individual case, successful treatment can scarcely be distinguished from a mild disease course. On the other hand, diagnostic nihilism is ethically unacceptable, as it would deprive patients who are destined to suffer from severe disease of potentially successful preventive treatment.

All experts who have taken a public position on these matters agree that neonatal screening is not just a laboratory test, but in fact a complex, integrated medical service with multiple components, including the obtaining and the submission of a sample, the laboratory analysis itself, the interpretation and communication of the findings, further confirmatory testing if necessary, and, finally, the initiation of any indicated treatment.

\section{The scope of expanded neonatal screening}

In accordance with the decision taken by the Joint Federal Committee (Gemeinsamer Bundesausschuss, GBA) on 21 December 2004 (15), the statutory health insurance carriers in Germany have been required to

\section{The consequences of tandem mass spectrometry}

Since the introduction of tandem mass spectrometry, there has been a doubling of the number of patients in whom metabolic disorders are diagnosed by screening.

\section{The purpose of neonatal screening}

is the universal early diagnosis of treatable endocrine and metabolic diseases in neonates, followed by the timely initiation of effective treatment. 
TABLE 1

The frequency of target diseases for neonatal screening among neonates in Germany, 2005-2008 (16)

\begin{tabular}{|c|c|c|c|c|}
\hline Diseases & $\begin{array}{l}\text { Verified cases } \\
2005-2008^{* 1}\end{array}$ & Frequency & Diagnostic markers / methods & $\begin{array}{l}\text { Urgency of } \\
\text { intervention }\end{array}$ \\
\hline \multicolumn{5}{|l|}{ Endocrinopathies } \\
\hline Hypothyroidism & 699 & $1: 3947$ & TSH/immunochemistry & B \\
\hline Adrenogenital syndrome (AGS) & 216 & $1: 12771$ & 17-OH-progesterone/immunochemistry & C \\
\hline \multicolumn{5}{|l|}{ Inborn metabolic defects } \\
\hline Biotinidase deficiency & 111 & $1: 24853$ & Activity/enzymatic & $E$ \\
\hline Galactosemia & 37 & $1: 74558$ & $\begin{array}{l}\text { Galactose and GALT activity/ } \\
\text { enzymatic }\end{array}$ & A \\
\hline \multicolumn{5}{|l|}{ Aminoacidopathies } \\
\hline $\begin{array}{l}\text { Phenylketonuria (PKU) and } \\
\text { hyperphenylalaninemia (HPA) }\end{array}$ & 494 & $1: 5584$ & Phenylalanine and Phe/Tyr quotient /TMS & $\mathrm{D}$ \\
\hline Maple syrup urine disease (MSUD) & 17 & $1: 162273$ & Leucine/isoleucine and valine/TMS & $A$ \\
\hline \multicolumn{5}{|l|}{ Fatty acid oxidation defects } \\
\hline $\begin{array}{l}\text { Medium-chain acyl-CoA dehydrogenase deficiency } \\
\text { (MCAD) }\end{array}$ & 260 & $1: 10610$ & Octanoylcarnitine/TMS & $\mathrm{D}$ \\
\hline $\begin{array}{l}\text { Long-chain 3-OH-acyl-CoA dehydrogenase } \\
\text { deficiency (LCHAD) }\end{array}$ & 13 & $1: 212202$ & $\begin{array}{l}\text { Hydroxyhexadecanoylcarnitine and } \\
\text { hydroxyoleylcarnitine/TMS }\end{array}$ & A \\
\hline $\begin{array}{l}\text { Very-long-chain acyl-CoA dehydrogenase } \\
\text { deficiency (VLCAD) }\end{array}$ & 31 & $1: 88988$ & $\begin{array}{l}\text { Tetradecanoyl- and tetradecadienoylcarnitine/ } \\
\text { TMS }\end{array}$ & A \\
\hline \multicolumn{5}{|l|}{ Carnitine cycle defects } \\
\hline Carnitine palmitoyl transferase I (CPT-I) deficiency & 5 & $1: 551727$ & Palmitoylcarnitine $(\downarrow)$ and free carnitine/TMS & $\mathrm{E}$ \\
\hline Carnitine palmitoyl transferase II (CPT-II) deficiency & 3 & $1: 919544$ & Long-chain acylcarnitines/TMS & A \\
\hline Carnitine acylcarnitine translocase (CAT) deficiency & 0 & & Long-chain acylcarnitines/TMS & A \\
\hline \multicolumn{5}{|l|}{ Organoacidemias } \\
\hline Glutaraciduria type I (GA I) & 22 & $1: 125392$ & Glutarylcarnitine/TMS & $E$ \\
\hline Isovaleric acidemia (IVA) & 24 & $1: 114943$ & Isovalerylcarnitine/TMS & $A$ \\
\hline Total & 1932 & $1: 1428$ & & \\
\hline
\end{tabular}

"Data from DGNS Screening Reports, 2005-2008 (a total of 2758633 children were screened).

For a detailed description of the screening tests and screening laboratories, see the DGNS Screening Reports (16).

A: Acute, life-threatening danger: immediate hospitalization in a primary treatment center for verification of the finding, confirmatory testing, and initiation of treatment, if indicated. For galactosemia screening, procedure A is indicated if the GALT activity is under $10 \%$, but only when artefacts have been judged to be unlikely and the galactose level is simultaneously elevated.

B: If the TSH level exceeds $50 \mu \mathrm{U} / \mathrm{mL}$, immediate outpatient presentation to a primary treatment center for the drawing of a blood sample to check the finding, and then immediate initiation of treatment with L-thyroxine, 10-15 $\mu \mathrm{g} / \mathrm{kg}$ (17). If the TSH level is below $50 \mu \mathrm{U} / \mathrm{mL}$, presentation to a primary treatment center for confirmatory testing and initiation of treatment, if indicated.

C: If the 17-OH-progesterone level is mildly elevated and/or confounding effects are present, the finding should be rechecked at once with another sample; if markedly elevated, immediate presentation to a primary treatment center for rechecking, confirmatory testing, determination of sodium and potassium levels, blood gas analysis, and renin concentration, and immediate initiation of treatment and counseling, if indicated.

D: Immediate outpatient presentation to a primary treatment center for rechecking, confirmatory testing, clinical chemistry test series, counseling, and initiation of treatment.

E: First, a blood sample is drawn to recheck the finding. If a pathological finding is confirmed, an outpatient appointment in a primary treatment center is scheduled as soon as possible for confirmation of the diagnosis and early initiation of treatment, on an inpatient basis if necessary. If glutaraciduria type I is suspected, a blood sample should be drawn before and after the administration of carnitine.

\section{Endocrinopathies}

Congenital hypothyroidism and adrenogenital syndrome (AGS) are treatable endocrinopathies that are detectable by neonatal screening.

\section{Life-threatening metabolic crises}

Maple syrup urine disease, fatty acid oxidation defects, and organoacidemias can cause life-threatening metabolic crises as early as the first week after birth. 


\section{Expanded neonatal screening: target diseases, clinical manifestations, and treatment}

\begin{tabular}{|c|c|c|}
\hline Disease & Main clinical manifestations if untreated & Principle of treatment \\
\hline Congenital (primary) hypothyroidism & $\begin{array}{l}\text { Often asymptomatic in neonates; may manifest itself } \\
\text { with prolonged jaundice, muscle hypotonia, weak drin- } \\
\text { king, and later severe developmental delay, growth } \\
\text { arrest, macroglossia, and constipation. } \\
\text { Note: TSH screening does not detect secondary or } \\
\text { tertiary hypothyroidism! }\end{array}$ & Lifelong L-thyroxine supplementation \\
\hline Adrenogenital syndrome (AGS) & $\begin{array}{l}\text { Virilization and, sometimes, salt-wasting syndrome } \\
\text { (neonatal onset) }\end{array}$ & $\begin{array}{l}\text { Lifelong supplementation of hydrocortisone and, } \\
\text { sometimes, mineralocorticoids }\end{array}$ \\
\hline Biotinidase deficiency & $\begin{array}{l}\text { Once the congenital biotin reserves are exhausted, } \\
\text { severe metabolic acidosis, ataxia, alopecia }\end{array}$ & Lifelong administration of 5-10 mg biotin p.o. q.d. \\
\hline Galaktosemia & $\begin{array}{l}\text { When milk (lactose) is ingested, severe hepatic } \\
\text { dysfunction, jaundice, coagulopathy, hepatomegaly, } \\
\text { cataracts (neonatal onset) }\end{array}$ & Lactose-free (galactose-free) diet for life \\
\hline Phenylketonuria & $\begin{array}{l}\text { Developmental delay, permanent brain damage, severe } \\
\text { mental retardation, epileptic seizures }\end{array}$ & Low-phenylalanine diet \\
\hline Maple syrup urine disease (MSUD) & $\begin{array}{l}\text { Weak drinking, somnolence, hypo- or areflexia, altered } \\
\text { muscle tone, epileptic seizures, respiratory insufficien- } \\
\text { cy, coma, urine smells like maple syrup (neonatal on- } \\
\text { set) }\end{array}$ & $\begin{array}{l}\text { Acute treatment: remove protein from diet, bring about } \\
\text { an anabolic state, perform dialysis if necessary } \\
\text { For life: low-leucine, low-valine, low-isoleucine diet }\end{array}$ \\
\hline $\begin{array}{l}\text { Medium-chain acyl-CoA dehydrogenase } \\
\text { deficiency (MCAD) }\end{array}$ & $\begin{array}{l}\text { Fever, vomiting, or fasting leads to a catabolic state } \\
\text { with hypoglycemia, epileptic seizures, coma, manifesta- } \\
\text { tions resembling Reye syndrome (hypoketotic hypogly- } \\
\text { cemia, hepatopathy, hyperammonemia, encephalopa- } \\
\text { thy) (neonatal onset is possible) }\end{array}$ & $\begin{array}{l}\text { Avoid fasting periods, frequent carbohydrate-rich } \\
\text { meals, carnitine p.o. }\end{array}$ \\
\hline $\begin{array}{l}\text { Long-chain 3-OH-acyl-CoA dehydrogenase } \\
\text { deficiency (LCHAD) }\end{array}$ & $\begin{array}{l}\text { Neonatal onset: hypoketotic hypoglycemia, lactic } \\
\text { acidosis, cardiomyopathy, elevated creatinine kinase; } \\
\text { Later: manifestations resembling Reye syndrome, } \\
\text { polyneuropathy, retinitis pigmentosa }\end{array}$ & $\begin{array}{l}\text { Diet very low in long-chain fats, replacement with } \\
\text { medium-chain triglycerides, carnitine p.o., avoidance of } \\
\text { fasting periods, frequent carbohydrate-rich meals }\end{array}$ \\
\hline $\begin{array}{l}\text { Very-long-chain acyl-CoA dehydrogenase } \\
\text { deficiency (VLCAD) }\end{array}$ & $\begin{array}{l}\text { Neonatal onset possible, as in LCHAD; otherwise, } \\
\text { cardiomyopathy and Reye-like manifestations (hepato- } \\
\text { encephalopathy) develop in the first months of life }\end{array}$ & $\begin{array}{l}\text { Diet very low in long-chain fats, replacement with } \\
\text { medium-chain triglycerides, carnitine p.o., avoidance of } \\
\text { fasting periods, frequent carbohydrate-rich meals }\end{array}$ \\
\hline $\begin{array}{l}\text { Carnitine palmitoyl transferase I (CPT-I) } \\
\text { deficiency }\end{array}$ & $\begin{array}{l}\text { Fasting intolerance, Reye-like manifestations (hepato- } \\
\text { encephalopathy) }\end{array}$ & $\begin{array}{l}\text { High-carbohydrate, low-fat diet, replacement with } \\
\text { medium-chain triglycerides, avoidance of fasting }\end{array}$ \\
\hline $\begin{array}{l}\text { Carnitine palmitoyl transferase II (CPT-II) } \\
\text { deficiency }\end{array}$ & $\begin{array}{l}\text { Neonatal type with myopathy, cardiomyopathy, hepato- } \\
\text { pathy, Reye-like manifestations; adult type with } \\
\text { exercise-induced rhabdomyolysis }\end{array}$ & $\begin{array}{l}\text { High-carbohydrate, low-fat diet, replacement with } \\
\text { medium-chain triglycerides, avoidance of fasting } \\
\text { periods }\end{array}$ \\
\hline $\begin{array}{l}\text { Carnitine acylcarnitine translocase (CAT) } \\
\text { deficiency }\end{array}$ & $\begin{array}{l}\text { Hypoketotic hypoglycemia, myopathy, } \\
\text { cardiomyopathy }\end{array}$ & $\begin{array}{l}\text { High-carbohydrate, low-fat diet, replacement with } \\
\text { medium-chain triglycerides, avoidance of fasting }\end{array}$ \\
\hline Glutaraciduria type I (GA I) & $\begin{array}{l}\text { Macrocephaly, frontotemporal brain atrophy, } \\
\text { hyperpyretic encephalopathic crises, development of a } \\
\text { dystonic-dyskinetic movement disorder }\end{array}$ & $\begin{array}{l}\text { High-calorie emergency treatment to prevent encepha- } \\
\text { lopathic crises, carnitine }\end{array}$ \\
\hline Isovaleric acidemia (IVA) & $\begin{array}{l}\text { Neonatal onset: weak drinking, vomiting, seizures, } \\
\text { encephalopathy, coma, marked ketoacidosis, sweaty } \\
\text { odor; mild, late-onset, and asymptomatic variants of the } \\
\text { disease are common }\end{array}$ & $\begin{array}{l}\text { Acute treatment: remove protein from diet, bring about } \\
\text { an anabolic state, glycine + carnitine, dialysis if neces- } \\
\text { sary. Long-term treatment: low-protein diet + carnitine + } \\
\text { glycine }\end{array}$ \\
\hline
\end{tabular}

\section{Adrenogenital Syndrome}

Adrenogenital syndrome can cause life-threatening salt wasting as early as the first week after birth or the next few weeks thereafter.

\section{Typical signs of salt-wasting syndrome}

- Weak drinking, vomiting, weight loss, apathy

- Serum values: low sodium and chloride, high potassium 
cover the costs of expanded neonatal screening since 1 April 2005. The GBA stated in its decision that tandem mass sprectrometry is the recommended standard method of metabolite screening. The decision contains procedural instructions and an official allotment of responsibilities, as well as a list of target illnesses for expanded neonatal screening. Table 1 contains an overview of the target diseases that were agreed upon, the number of confirmed cases from 2005 to 2008 (16), the disease frequencies that can be calculated from these figures, and the interventions that are necessary when findings are positive.

Any testing procedure that is to be used to screen neonates for a rare disease must be both highly sensitive, in order to capture all of the actual cases of the disease, and highly specific, in order to yield no more than a small percentage of false positive results. If, for example, a test with $100 \%$ sensitivity yields a positive result in $0.1 \%$ of all neonates tested, but the disease being tested for is present in only $0.01 \%$ of these neonates, then the positive predictive value of the test is only $10 \%$; in other words, 9 out of 10 neonates with a positive test result will actually be healthy. The follow-up tests that will be performed to check the initially positive results will give rise to unnecessary stress for these babies' families and unnecessary costs for the health care system. TMS is much more specific than the above numerical example: The predictive value of a positive test by TMS for hyperphenylalaninemia (PKU/HPA) (for example) is $55 \%$. This means that more than half of all positive test results will be confirmed by repeated testing. On the other hand, the predictive value of a positive immunohistochemical test for $17-\mathrm{OH}-$ progesterone screening is only about $3 \%$; thus, to identify a single neonate with AGS, follow-up testing must be performed in about 30 neonates with initially positive tests. The following average figures for the specificity of the test procedures used were reported for the years 2005 to 2008 (16):

- Hypothyroidism $99.88 \%$

- Adrenogenital syndrome $99.39 \%$

- Biotinidase deficiency $99.98 \%$

- Galactosemia $99.93 \%$

- TMS (all target diseases together) $99.86 \%$.

The expansion of the neonatal screening program has enabled the presymptomatic diagnosis and treatment of a number of diseases that previously led to severe metabolic disturbances in neonates, resulting in encephalopathy and coma, often in the first few days or weeks of life. Maple syrup urine disease and the fatty acid oxidation defects and organoacidemias can take a fatal course in neonates, or else the metabolic disturbance can cause permanent damage. Prerequisites for the presymptomatic detection and treatment of these diseases are an early timepoint for screening, flawless organization, and rapid execution of the entire screening process, up to the moment that treatment is begun. The advantage of an early screening timepoint is most evident for the fatty acid oxidation defects, because the physiological catabolic state that is present in the days just after birth enables more reliable detection of abnormal metabolite patterns. Of course, this catabolic state is also associated with the danger of early metabolic decompensation, in case the child has one of the diseases mentioned above. The main clinical manifestations of the target diseases and the treatment options for each are listed in Table 2. In its decision, the Joint Federal Committee explicitly did not permit the obtaining of further data for purposes other than the detection of a target disease that is on this list. The Joint Federal Committee plans to review the screening program, and to update it if necessary, once every two years.

The Joint Federal Committee's decision has led to the implementation of a uniform standard for the scope and methods of screening in the 15 German laboratories that currently analyze neonatal screening specimens. The results from all of these laboratories for the years 2005 to 2008 are now available (16). On average, one target disease was detected for every 1428 specimens submitted. The expansion of the neonatal screening program in 2005 led to a $57 \%$ increase in the overall rate of detection of diseases, with a $92 \%$ increase for the metabolic diseases alone.

Neonatal screening in other European countries is highly variable. In some places, the necessary resources and infrastructure are lacking. A few countries, such as the United Kingdom, have not yet undertaken any major expansion of their screening programs because of economic constraints. Austria, Switzerland, and the Netherlands have neonatal screening programs that are comparable to the one in Germany.

\section{The performance of screening}

The organizational measures that are to be taken when neonatal screening is performed were laid down in 2002 in the screening guidelines of the DGKJ (10) and

\section{The duty to inform}

Before the sample is taken, the child's parents must be informed by a physician about the nature and purpose of screening. At least one parent must give written consent.

\section{Neonatal screening across Europe}

Neonatal screening elsewhere in Europe is variable. Some countries lack the needed resources and infrastructure; a few others have not yet undertaken any major expansion of their screening programs because of economic constraints. 


\section{Neonatal screening: procedures and responsibilities}

\section{Specimen collection and submission}

- Before screening is performed, the child's parents must be informed about its nature and purpose (with the aid of an information sheet). ${ }^{*}$

- At least one parent must consent in writing. ${ }^{* 2}$

- The blood sample should be obtained on the third day of life (i.e., two days after birth; specifically, between 36 and 72 hours after birth).

- If the blood sample is not obtained in this time period, it should be obtained as soon as possible thereafter.

- If the neonate is discharged from the hospital less than 36 hours after birth, a first specimen must be obtained before discharge and the parents must be informed of the necessity of taking a second specimen on the third day of life (second screening).

- The specimen is obtained by allowing native venous blood or blood from the child's heel (without additives!) to drip onto filter paper cards issued by the screening laboratories, on which all patient data have been entered. Venous blood drawing is less painful.

- The specimen is allowed to dry for one hour at room temperature (never heat the sample!).

- The taking of the specimen is documented in the pediatric test chart (yellow test chart): the date and time the specimen was taken and the address of the screening laboratory are recorded.

- The specimen is sent to the screening laboratory on the day it was taken (date of specimen = mailing date).

\section{Specimen processing}

- The screening laboratory must be accredited for all aspects of expanded neonatal screening. At least 50000 initial screenings per year are required for reasons of quality assurance and economic efficiency.

- All laboratory analyses of a single specimen must be performed in the same laboratory (specimen splitting is forbidden).

- The screening laboratory performs the testing on the same day that the specimen is received. This implies that the laboratory must be able to process specimens on any day that the postal service is in operation (six-day workweek).

\section{Reporting of findings}

- If the presence of a target disease is suspected, the screening laboratory must immediately inform the physician who submitted the specimen and request a second specimen to check the finding. The manner in which the finding is reported, and the procedure subsequently agreed upon, are to be documented in writing.

- The physician who submitted the specimen, after being informed of the positive finding, relates it in turn to the child's parents immediately and informs them that further specialized testing must be performed without delay. The communication of the finding to the parents is to be documented in writing.

- Normal findings of neonatal screening are communicated to the submitting physician in writing. The physician checks that a a report of the findings has been received for each submitted specimen.

\footnotetext{
${ }^{* 1}$ Specimens for neonatal screening may be obtained either under a physician's supervision or by a midwife, as not all children are born in hospitals, and the first check-up by a pediatrician (the U2 check-up, on the 3rd to 10 th day of life) may be too late for useful screening. Nonetheless, it remains clear that the information and counseling of a child's parents with neonatal screening are tasks that may be performed only by a physician. Therefore, midwives should obtain neonatal screening specimens in timely fashion under the direction of a physician who is responsible for parent information and counseling.

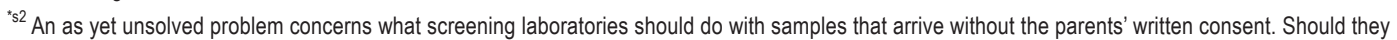
process the specimen, in view of the fact that immediate processing serves to identify immediate dangers, or must they await written consent, which may merely have been forgotten or unintentionally omitted? This is a recurring problem in the practical implementation of screening.
}

\section{When the blood sample should be taken}

The rule for neonatal screening in Germany is that the blood sample should optimally be obtained on the third day of life (i.e., two days after birth), and no sooner than 36 hours after birth.
What should be done after the sample is taken The screening card with drops of whole blood on it is allowed to dry for one hour at room temperature and is then sent to the screening laboratory on the same day. 


\section{Potential sources of error}

\section{Factors that may lead to error:}

\section{A. Specimen taken too early}

- In many neonates, the serum levels of TSH and 17-OH-progesterone are still high right after birth. Moreover, as a consequence of the transplacental dialysis that functions until birth, the disease-specific metabolite profile of a metabolic disease may not be apparent in full severity in the first few hours after birth. For these reasons, a second screening is required for all neonates whose first screening specimen was obtained less than 36 hours after birth.

\section{B. Premature birth}

- Premature neonates have high $17-\mathrm{OH}$-progesterone levels. Even when adapted reference ranges are used, screening is often positive, necessitating rechecking of the level with a further test.

- Congenital hypothyroidism is not reliably detectable in neonates born earlier than the 32nd week of gestation. A normal finding must be followed up by a second screening at 32 weeks of corrected gestational age.

\section{Medical treatment}

- Corticosteroid administration: false normal findings, particularly for $17-\mathrm{OH}$ progesterone. Retesting should be performed two weeks after corticosteroids are discontinued.

- Catecholamine administration: false normal findings for TSH; biotinidase activity may be low. Retesting should be performed two weeks after catecholamines are discontinued.

- Parenteral nutrition: nonspecific elevation of amino acid levels can mask disease-specific laboratory profiles. Lack of catabolism makes the detection of fatty acid oxidation defects less sensitive. Blood drawing four hours after temporary cessation of parenteral nutrition is advisable.

- lodine exposure: may cause false positive TSH findings.

- Blood transfusion and/or administration of fresh frozen plasma (FFP): these may lead to false normal findings in all screening tests. Thus, a blood sample for neonatal screening should always be obtained before transfusion, even if less than 36 hours have elapsed since birth. Screening should be repeated two weeks after the transfusion. If no sample was obtained before transfusion, two screening tests should be performed, two weeks and six to eight weeks after transfusion.

\section{Potential generators of artefact:}

- Heating the screening card: this destroys enzymatic activity and thus generates false pathological findings of galactosemia and biotinidase screening.

- Contamination with disinfectants: this also destroys enzymatic activity.

- Contamination with mother's milk: falsely abnormal findings of galactosemia screening.

- Contamination with EDTA: false negative findings for TSH, false elevation of 17-OH-progesterone level, inaccurate galactosemia screening. were incorporated thereafter in the decision of the Joint Federal Committee (15). Abnormal findings must be reported no later than 72 hours after the taking of the specimen (Box 1).

\section{Potential sources of error in screening}

The experience of the past few decades has shown that about two-thirds of all errors in screening are due to faulty organization. Nonetheless, a few individual sources of error are presented here in Box 2. These include both patient-related factors and external generators of laboratory artefact.

\section{Confirmation of the diagnosis and initiation of treatment}

In its 2002 guidelines (10), the DGKJ advocated the creation of regional screening centers to ensure implementation of the complex overall medical service of neonatal screening throughout the Federal Republic of Germany. The regional screening centers consist of the primary treatment centers, the public health departments, and the screening laboratories that carry out the testing; their purpose is to perform neonatal screening of assured quality as an integrated overall service. Data generated by the regional screening centers can be used to check the efficiency of the neonatal screening system.

According to the Screening Committee's guidelines, a primary treatment center must meet the following criteria:

- Specially trained medical staff with expert knowledge of the diagnostic evaluation, counseling, and long-term treatment of patients with congenital endocrinopathies and metabolic disorders

- Continuous availability of expert medical staff

- Continuous availability of diagnostic testing to confirm the diagnoses and monitor the treatment of the diseases treated in the center.

To care for patients with congenital metabolic disorders, the following must also be available:

- Intensive care for neonates and older children as needed, including blood-cleansing procedures such as dialysis and continuous veno-venous hemofiltration, for treatment and detoxification in case of acute metabolic decompensation

- A pediatric dietetic service with experience in the long-term care of patients with congenital metabolic defects such as phenylketonuria, maple syrup urine disease, organoacidurias, and others.

\section{Screening laboratories}

Screening laboratories process samples on the day they are received and can generally report the results within 24 hours.

\section{Potential sources of error}

About two-thirds of all errors in the screening process are due to faulty organization. 


\section{The further scientific development of neonatal screening}

In 1968, Wilson and Jungner already included continuous scientific development among the important elements of a properly functioning screening program. The correctness of this judgment is even more evident now that the neonatal screening program has been expanded: If the relevant preliminary scientific studies, such as the Bavarian model trial, had not been performed, then expanded neonatal screening could never have been introduced in its present form. New types of successful treatment for congenital metabolic defects are sure to come in future as well. A number of screening laboratories have been performing screening for cystic fibrosis (mucoviscidosis) for some time now. This involves, as a first step, the measurement of immunoreactive trypsin (IRT). Until now, samples with unusually high IRT values were further studied by mutational analysis. This technique is expected to be supplanted by the measurement of pancreatitis-associated protein, so that the problems associated with DNA analysis can be avoided (18). On the other hand, alpha 1-antitrypsin deficiency is an example of a disease that is unsuitable for neonatal screening, because, depending on the particular form that is present, overt disease never develops at all (which is true in most cases), or, if it does, then only in adulthood. Nor is there any treatment that is currently recognized to be effective. Alpha 1-antitrypsin measurement is already a standard component of the diagnostic evaluation of pulmonary and hepatic diseases.

The decision of the Joint Federal Committee requires blinding of all data that do not contribute to the detection of the target diseases that are currently being sought, but this need not stand in the way of the further development of the screening program, nor would such an outcome be consistent with the Joint Federal Committee's original intent. It remains to be decided which diseases will be investigated in future pilot projects for neonatal screening, and what the conditions of these projects will be. In view of the rapidly expanding possibilities of diagnostic testing, e.g., with high-throughput DNA analysis, it would seem wiser to incorporate useful preventive tests of this type in an already functioning screening program, rather than leave them up to the "gray market" of individually delivered health care services (19).

\section{Neonatal screening and the German Law on Genetic Diagnosis}

The new German Law on Genetic Diagnosis (Gendiagnostikgesetz, GenDG) (20) has given rise to concern among persons involved in neonatal screening. Expanded neonatal screening was evidently neither the motivation nor the target of this legislative measure. The text of the law as it was passed does not contain the word "screening." In the Government's original draft legislation, however, there is an explanatory statement that deals extensively with neonatal screening and expresses a clear position on it (explanatory statement accompanying $\S 16$ on population-wide genetic testing [21]). According to this statement, expanded neonatal screening as introduced on 1 April 2005 is to be continued in its present form and with the agreed-upon scope and is not to be subjected to a review for compliance with the provisions of the GenDG, as the latter took effect after expanded neonatal screening was already in place. Nonetheless, it remains to be seen whether future changes or expansions of the neonatal screening program will have to be reviewed by the Genetic Diagnosis Committee before additional types of testing can be introduced as a general measure.

The provisions of the GenDG apply to all tests that search for genetic mutations on the molecular level. An unintended, and indeed undesired, by-product of DNA analysis is that it identifies phenotypically healthy heterozygous carriers of genetic traits. Thus, genetic traits that have no pathological significance are detected in individuals (children) who are incapable of consenting to genetic testing. The right to autonomy with respect to personal information includes not just the right to know, but also the right not to know. Children are not yet capable of asserting their right to autonomy with respect to personal information, and parents cannot assert it on their behalf unless diagnostic testing is urgently needed for the detection of a disease that is treatable in childhood (GenDG § 14). Only in such cases does the parental duty of care take precedence over the child's autonomy. The unsolved problem of the physician's duty to inform when a child has been identified as a phenotypically healthy heterozygous carrier will have to be dealt with before mutational analysis is carried out in large numbers of healthy children who cannot themselves consent to testing. Any regulation concerning this matter should also take account of the potential

\section{Pilot projects on neonatal screening}

Pilot projects on neonatal screening for cystic

fibrosis (mucoviscidosis) have been in progress

for some time in a number of screening

laboratories.

\section{The German Law on Genetic Diagnosis (Gendiagnostikgesetz, GenDG)}

All tests involving a search for genetic mutations

on the molecular level clearly fall within the scope of the German Law on Genetic Diagnosis. 
effects such undesired findings might have on other family members.

\section{The limitations of neonatal screening}

Recent years have seen the development of a market of purveyors of preventive diagnostic tests that are said to represent a useful complement to neonatal screening. Testing of this kind is an individual health service and should not be considered in the same category as a population-wide genetic test such as neonatal screening. Almost all such tests involve the use of molecular genetic technology to search for mutations that can cause disease or impair health. In fact, however, some of these mutations actually do not cause overt disease except in a small minority of cases, and others do not cause disease in childhood, but only in later life; finally, some of the mutations for which testing is being offered cause diseases for which there is no treatment, such as alpha 1-antitrypsin deficiency. The Law on Genetic Diagnosis (GenDG $\S 14$ ) permits such tests to be performed in children who are incapable of giving informed consent exclusively for the avoidance, treatment, or prevention of genetically determined diseases or health impairments that arise before the child's $18^{\text {th }}$ birthday, and that are treatable. If these conditions are not met, the child's right to autonomy with respect to personal information takes precedence over the parental duty of care. The purveyors of such tests profit from the worries of young parents who want only to do the right thing for their children but who, in fact, purchase nothing more than additional worries. Interestingly, these tests are generally peddled to the parents of newborn children via midwives, rather than pediatricians. It would be a highly welcome development if the implementation of the Law on Genetic Diagnosis were to put an end to this type of rampant genetic voyeurism.

\section{Conflict of interest statement \\ The authors declare that they have no conflict of interest as defined by the guidelines of the International Committee of Medical Journal Editors.}

Manuscript submitted on 31 May 2010, revised version accepted on 18 November 2010 .

Translated from the original German by Ethan Taub, MD.

\section{REFERENCES}

1. Grosse SD, Khoury MJ, Greene CL, Crider KS, Pollitt RJ: The epidemiology of medium chain acyl-CoA dehydrogenase deficiency: An update. Genet Med 2006; 8: 205-12.
2. Ogier de Baulny H, Saudubray JM: Branched-chain organic acidurias. Semin Neonatol 2002; 7: 65-74.

3. Bickel H, Gerrard J, Hickmans EM: Preliminiary communication: Influence of phenylalanine intake on phenylketonuria. Lancet 1953 262: 812-3.

4. Guthrie R, Susi A: A simple phenylalanine method for detecting phenylketonuria in large populations of newborn infants. Pediatrics 1963; 32: 338-42.

5. Klett M, Schönberg D: Neugeborenen-Hypothyreose-Screening in der Bundesrepublik Deutschland: Ergebnisse einer Umfrage. Dtsch med Wochenschr 1981; 106: 6-12.

6. Schnabel D, l'Allemand D, Krude H, Keller E, Grüters A: Ergebnisse des Neugeborenenscreenings zur Früherkennung des Adrenogenitalen Syndroms in Berlin (1992-1999). Monatsschr Kinderheilkd 2000; 148: 1006-11.

7. Chace DH, DiPerna JC, Naylor EW: Laboratory integration and utilization of tandem mass spectrometry in neonatal screening: a model for clinical mass spectrometry in the next millennium. Acta Paediatr Suppl 1999; 88: 45-47.

8. Liebl B, Fingerhut R, Röschinger W et al.: Modellprojekt zur Neuordnung des Neugeborenen-Screenings in Bayern: Konzeption und erste Ergebnisse. Gesundheitsw 2000; 62: 189-95.

9. Roscher AA, Fingerhut R, Liebl B, Olgemöller B: Erweiterung des Neugeborenenscreenings durch Tandemmassenspektrometrie. Monatsschr Kinderheilkd 2001; 149: 1297-1303.

10. Harms E, Roscher AA, Grüters A, et al.: Neue Screening-Richtlinien: Richtlinien zur Organisation und Durchführung des Neugeborenenscreenings auf angeborene Stoffwechselstörungen und Endokrinopathien in Deutschland. Monatsschr Kinderheilkd 2002; 150: 1424-9.

11. Wilson JMG, Jungner G: Principles and practice of screening for disease; 1968. WHO bulletin: http://www.who.int/bulletin/vol umes/86/4/07-050112bp.pdf

12. Andermann A, Blancquaert I, Beauchamp S, Déry V: Revisiting Wilson and Jungner in the genomic age: a review of screening criteria over the past 40 years. WHO bulletin 2008; 86: 317-9.

13. Pollitt RJ, Greene A, McCabe CJ, et al.: Neonatal screening for inborn errors of metabolism: cost, yield and outcome. Health Technol Assess 1997; 1(7).

14. Pandor A, Eastham J, Beverley C, Chilcott J, Paisley S: Clinical effectiveness and cost-effectiveness of neonatal screening for inborn errors of metabolism using tandem mass spectrometry: a systematic review. Health Technol Assess 2004; 8 (12).

15. Bekanntmachung eines Beschlusses des Gemeinsamen Bundesausschusses über eine Änderung der Richtlinien des Bundesausschusses der Ärzte und Krankenkassen über die Früherkennung von Krankheiten bei Kindern bis zur Vollendung des 6. Lebensjahres (Kinder-Richtlinien) zur Einführung des erweiterten NeugeborenenScreenings. BAnz. Nr. 60 vom 31.03.2005, 4833-8.

16. Nationale Screeningreports der Deutschen Gesellschaft für das Neugeborenenscreening (DGNS): http://www.screening-dgns.de/ screeningregister-1.htm

17. Grüters A, Delange F, Giovannelli G, et al.: Guidelines for neonatal screening programmes for congenital hypothyroidism. Eur J Pediatr 1993: 152: 974-5

\section{Preventive diagnostic testing}

Preventive diagnostic testing is an individual health service (IHS) and is thus distinct from population-wide genetic testing, such as neonatal screening. 
18. Sarles J, Berthézène P, Le Louarn C, et al.: Combining immunoreactive trypsinogen and pancreatitis-associated protein assays, a method of newborn screening for cystic fibrosis that avoids DNA analysis. J Pediatr 2005; 147:302-5.

19. Fingerhut R, Olgemöller B: Newborn screening for inborn errors of metabolism and endocrinopathies: an update. Anal Bioanal Chem 2009; 393: 1481-97.

20. Gesetz über genetische Untersuchungen beim Menschen (2009) Bundesgesetzblatt, S. 2529-37.

21. Entwurf eines Gesetzes über genetische Untersuchungen bei Menschen (Gendiagnostikgesetz - GenDG) 2008, Bundestagsdrucksache 16/10532: http://dip21.bundestag.de/ dip21/btd/16/105/1610532.pdf

\section{Corresponding author}

Prof. Dr. med. Erik Harms

Einener Str. 10

48291 Telgte, Germany

harms@uni-muenster.de

\section{Further Information on GME}

This article has been certified by the North Rhine Academy for Postgraduate and Continuing Medical Education.

Deutsches Ärzteblatt provides certified continuing medical education (CME) in accordance with the requirements of the Medical Associations of the German federal states (Länder). CME points of the Medical Associations can be acquired only through the Internet, not by mail or fax, by the use of the German version of the CME questionnaire within 6 weeks of publication of the article. See the following website: cme.aerzteblatt.de

Participants in the CME program can manage their CME points with their 15-digit "uniform CME number" (einheitliche Fortbildungsnummer, EFN). The EFN must be entered in the appropriate field in the cme.aerzteblatt.de website under "meine Daten" ("my data"), or upon registration. The EFN appears on each participant's CME certificate.

The solutions to the following questions will be published in issue 9/2011. The CME unit "Idiopathic Scoliosis" (issue 49/2010) can be accessed until 21 January 2011. For issue 5/2011 we plan to offer the topic "The Treatment of Spinal Metastases."

Solutions to the CME questionnaire in issue 45/2010: Schneider T, Mawrin C, Scherlach C, Skalej M, Firsching R: Gliomas in Adults.

Answers: 1b, 2a, 3c, 4b, 5b, 6c, 7a, 8d, 9d, 10b 


\section{Please answer the following questions to participate in our certified Continuing Medical Education program. Only one answer is possible per question. Please select the answer that is most appropriate.}

Question 1

When should a blood sample be drawn for neonatal screening, according to the current rules in Germany?
a) At the time of the U2 check-up
b) At the time of the U1 check-up
c) Two days after birth
d) On the day of birth
e) In the first week after birth

\section{Question 2}

What metabolic state is typical in defects of fatty acid oxidation?
a) Hypoketotic hypoglycemia
b) Ketotic hypoglycemia
c) Ketotic hyperglycemia
d) Respiratory alkalosis
e) Metabolic alkalosis

\section{Question 3}

How is phenylketonuria treated, if it needs to be treated?
a) With a low-phenylalanine diet
b) With a phenylalanine-free diet
c) With a reduced-protein diet
d) With a high-tyrosine diet
e) With a high-carbohydrate diet containing no natural protein

\section{Question 4}

With the screening methods currently in use, which of the following is most likely to be found as a false positive laboratory result?
a) Hypothyroidism
b) Adrenogenital syndrome
c) Galactosemia
d) Phenylketonuria
e) MCAD deficiency

\section{Question 5}

A screening test performed two days after birth yields a TSH value of $65 \mu \mathrm{U} / \mathrm{mL}$. What must be done?

a) Thyroid ultrasonography

b) Scintigraphy

c) Another check when the baby is 4 weeks old

d) Blood drawing for a baseline sample and immediate initiation of treatment

e) Treatment as soon as the baseline value has been received from the testing laboratory
Question 6

Which of the following target conditions for neonatal screening should be retested by repeated screening after the 32nd week of gestation (corrected date), if the first screening test for it was positive in a premature infant born before the end of the 32nd week?
a) Phenylketonuria
b) Hypothyroidism
c) Biotinidase deficiency
d) Galactosemia
e) VLCAD deficiency

\section{Question 7}

Which of the following diagnoses, if suspected on the basis of a neonatal screening test, necessitates immediate hospitalization and treatment of the infant because of an acute threat to life?
a) Biotinidase deficiency
b) Glutaraciduria type I
c) MCAD deficiency
d) Phenylketonuria
e) Maple syrup urine disease

\section{Question 8}

If the predictive value of a positive screening test for a certain disease is $2 \%$, how many individuals will test positive for every person who actually has the disease?
a) 5
b) 10
c) 20
d) 50
e) 100

\section{Question 9}

In which of the following diseases are the clinical manifestations of Reye syndrome (hepatic encephalopathy) typically seen?
a) Maple syrup urine disease
b) Fatty acid oxidation defect
c) Biotinidase deficiency
d) Galactosemia
e) Adrenogenital syndrome with salt wasting

\section{Question 10}

In neonatal screening, what is the maximum allowable interval of time from the receipt of a blood sample in the laboratory to the completion of blood tests?
a) 1 day
b) 3 days
c) 5 days
d) 7 days
e) 2 weeks 